\title{
NITROGÊNIO E ENXOFRE NA PRODUÇÃO E NO USO DE ÁGUA PELO CAPIM-BRAQUIÁRIA EM DEGRADAÇÃ̃O ${ }^{(1)}$
}

\author{
Edna Maria Bonfim-Silva ${ }^{(2)}$, Francisco Antonio Monteiro $^{(3)}$ \\ \& Tonny José Araújo da Silva ${ }^{(4)}$
}

\begin{abstract}
RESUMO
O N tem sido indispensável na formação, manutenção e recuperação de pastagens e seu efeito tem mostrado ser dependente do suprimento de $\mathrm{S}$. Assim, com base na hipótese de que o incremento de $\mathrm{N}$ na adubação torna necessário aumentar o fornecimento de S para recuperar o capim-braquiária (Brachiaria decumbens Stapf) e de que a adubação melhora também a eficiência no uso de água pelo capim, objetivou-se avaliar a recuperação do capim-braquiária, mediante fornecimento de doses de $\mathrm{N}$ e de $\mathrm{S}$, por meio da área foliar, a produção de massa seca da parte aérea e o consumo e a eficiência no uso de água pelo capim. Coletaram-se amostras indeformadas de solo em cilindros de $15 \mathrm{~cm}$ de diâmetro e $20 \mathrm{~cm}$ de profundidade com capim-braquiária + solo de uma pastagem em estádio de degradação. $\mathrm{O}$ solo foi classificado como Neossolo Quartzarênico. O experimento foi realizado em casa de vegetação, em Piracicaba-SP, no período de novembro de 2003 a março de 2004. Foram combinadas cinco doses de N $(0,100,200,300$ e $\left.400 \mathrm{mg} \mathrm{dm}^{-3}\right)$ com cinco doses de $\mathrm{S}\left(0,10,20,30\right.$ e $\left.40 \mathrm{mg} \mathrm{dm}^{-3}\right)$, num estudo de superfície de resposta baseado em desenho experimental composto central modificado de um fatorial $5^{2}$ fracionado. Foram realizados três cortes nas plantas, com intervalos regulares de 30 dias. A interação entre as doses de $\mathrm{N}$ e de $\mathrm{S}$ foi significativa apenas no primeiro crescimento do capim, com exceção da área foliar, para a qual essa interação foi significativa no primeiro e no segundo crescimento. Houve efeito isolado do $\mathrm{N}$ no segundo e no terceiro crescimento. $\mathrm{O}$ fornecimento simultâneo de N e S na adubação contribuiu na recuperação do capim-braquiária, aumentando a área foliar e a produção de massa seca, elevando o consumo e a eficiência no uso de água pela planta.
\end{abstract}

Termos de indexação: área foliar, Brachiaria decumbens, produção de massa seca.

\footnotetext{
(1) Parte da Tese de Doutorado do primeiro autor, apresentada à Escola Superior de Agricultura "Luiz de Queiroz" - USP. Projeto com apoio financeiro FAPESP. Recebido para publicação em junho de 2005 e aprovado em janeiro de 2007.

(2) Zootecnista, Pós-Doutora em Solos e Nutrição de Plantas pela Escola Superior de Agricultura "Luiz de Queiroz" - USP. Av. Pádua Dias 11, CEP 13418-900 Piracicaba (SP). Bolsista do CNPq. E- mail: embonfim@hotmail.com

(3) Professor Titular, Departamento de Ciência do Solo, ESALQ/USP. Bolsista do CNPq. E-mail: famontei@esalq.usp.br

(4) Professor Adjunto da Universidade Federal Rural de Pernambuco - Unidade Acadêmica de Garanhuns (PE), UFRPE-UAG. Av. Ernesto Dourado 82, CEP 55296-280 Garanhuns (PE). E-mail: tonny.silva@pesquisador.cnpq.br
} 


\title{
SUMMARY: NITROGEN AND SULPHUR ON YIELD AND WATER USE EFFICIENCY OF SIGNALGRASS FROM A DEGRADING AREA
}

\begin{abstract}
Nitrogen is indispensable for pasture establishment, maintenance and production recovery, and its effect is apparently dependent on sulphur supply. It was hypothesized that increasing nitrogen supply requires higher sulphur rates to recover signalgrass (Brachiaria decumbens Stapf.), and that fertilization increases the water use efficiency by plants. The leaf area, dry matter yield, water consumption, and water use efficiency of the grass were evaluated under the application of nitrogen and sulphur rates. Cylinders of 15 $\mathrm{cm}$ diameter and $20 \mathrm{~cm}$ depth were used to collect signalgrass + undisturbed soil from an Entisol with degrading pasture. The experiment was carried out in a greenhouse, in Piracicaba, São Paulo State, Brazil, from November 2003 through March 2004. Five rates of nitrogen (0;100;200; 300 and $\left.400 \mathrm{mg} \mathrm{dm}^{-3}\right)$ and sulphur $\left(0 ; 10 ; 20 ; 30\right.$ and $\left.40 \mathrm{mg} \mathrm{dm}^{-3}\right)$ were tested by the response-surface methodology based on a modified central composite design of a $5^{2}$ fractional factorial scheme. Three harvests were performed in 30 day intervals. The interaction between nitrogen and sulphur rates was significant for the first harvest only, with exception of leaf area for which this interaction was significant for the second harvest as well. The effects of nitrogen were significant in the second and third harvest only. The concomitant supply of nitrogen and sulphur to signalgrass increased leaf area, forage yield, water consumption and use efficiency.
\end{abstract}

Index terms: Brachiaria decumbens, dry matter yield, leaf area.

\section{INTRODUÇÃO}

No Brasil, a forma extrativista de exploração pecuária vem aumentando as áreas de pastagem degradada ou em processo de degradação (Souza Neto \& Pedreira, 2004). Na degradação das pastagens, a produtividade e a composição botânica podem ser substancialmente alteradas ao longo do tempo, devido ao declínio da fertilidade do solo e ao manejo inadequado das plantas forrageiras (Mattos \& Monteiro, 2003). O esgotamento da fertilidade do solo, em conseqüência da ausência de adubação, tem sido apontado como uma das principais causas da degradação de pastagens cultivadas.

As estratégias utilizadas para a recuperação da capacidade produtiva da pastagem buscam interromper o processo de degradação com base nas causas a ela associadas (Carvalho, 1999). Assim, a reconstituição da fertilidade do solo passa a ser uma alternativa técnica para a recuperação dessas áreas, e as adubações com $\mathrm{N}$ e $\mathrm{S}$ se inserem nesse contexto.

O N é o grande responsável pelo aumento da produtividade das gramíneas forrageiras e o seu efeito tem mostrado ser dependente do S, pela relação entre esses nutrientes no metabolismo vegetal (Batista, 2002; Rodrigues, 2002; Mattos \& Monteiro, 2003). A planta forrageira com deficiência de $\mathrm{N}$ responde pouco ao S. Contudo, em alta disponibilidade de N é maior a exigência por $\mathrm{S}$, uma vez que este nutriente é importante no metabolismo do $\mathrm{N}$ e na síntese de proteína (Werner \& Monteiro, 1988).

Para recuperação da pastagem, outro fator que precisa ser considerado é a necessidade de que os nutrientes fornecidos estejam disponíveis e sejam absorvidos pelas plantas. Sabe-se que a absorção dos nutrientes depende, entre outros fatores, da disponibilidade de água no solo e que, tanto para o $\mathrm{N}$ como para o S, o transporte até as raízes é essencialmente efetuado por fluxo de massa. Daí decorre a necessidade de garantir quantidade adequada de água para o desenvolvimento da planta. A água forma o ambiente onde ocorre a maioria das reações bioquímicas celulares, e ela participa diretamente em muitas reações químicas essenciais (Taiz \& Zeiger, 2004).

A transpiração é uma forma eficiente de dissipar o calor proveniente do sol. O calor dissipa-se porque as moléculas de água que escapam para a atmosfera têm energia maior que a média, o que promove rompimento das ligações que as seguram na forma líquida. Quando tais moléculas escapam, elas deixam para trás uma massa de moléculas com energia menor que a média e, portanto, um corpo líquido mais frio. Quase metade do ganho líquido de calor do sol é dissipada pela transpiração. Além disso, o fluxo da água absorvida pela planta é uma importante via de condução de nutrientes dissolvidos do solo até a superfície radicular, para que ocorra a absorção (Taiz \& Zeiger, 2004), sendo muito significativo para o $\mathrm{N} \mathrm{e} \mathrm{S}$, os quais são absorvidos por fluxo de massa.

Durante o ciclo de vida da planta, uma quantidade de água equivalente a 100 vezes a massa do material verde dela pode ser perdida através das superfícies foliares. Essa perda de água se dá pela transpiração (Taiz \& Zeiger, 2004), que, quando associada à evaporação do solo, passa a compor a evapotranspiração. 
No entanto, o que tem sido observado é que, quando a planta está adequadamente nutrida, além de expressar o seu potencial genético produtivo, também pode ser mais eficiente na absorção e utilização de água no solo (Silva et al., 2001; Soria et al., 2003).

Desse modo, tem-se por hipótese que a adubação nitrogenada requer fornecimento adequado de $\mathrm{S}$ para recuperar o capim-braquiária (Brachiaria decumbens Stapf.) e que a adubação com esses dois nutrientes melhora a eficiência no uso de água pelo capim. Assim, objetivou-se avaliar a recuperação do capim com quantificação da área foliar, a produção de massa seca da parte aérea e a eficiência no uso de água, quando doses de $\mathrm{N}$ e $\mathrm{S}$ foram fornecidas ao capim-braquiária em solo provenientes de pastagem em degradação.

\section{MATERIAL E MÉTODOS}

O experimento foi realizado em casa de vegetação, em Piracicaba, São Paulo, no período de novembro de 2003 a março de 2004. Optou-se por realizar esse experimento em condições controladas, em vista da possibilidade de estudar uma ampla série de combinações entre cinco doses de cada um dos nutrientes, evitando interferências de animais em pastejo, além de garantir o fornecimento de água e de temperatura ambiente adequados para o crescimento e desenvolvimento das plantas.

Coletaram-se amostras indeformadas de solo em cilindros de $15 \mathrm{~cm}$ de diâmetro e $20 \mathrm{~cm}$ de profundidade com capim-braquiária + terra em um Neossolo Quartzarênico, numa pastagem em estádio de degradação, no município de Santa Maria da SerraSP. Essas amostras de solo e plantas foram colocadas em vasos plásticos, conforme técnica descrita por Mattos \& Monteiro (2003). Durante 30 dias as plantas foram adaptadas e os vasos homogeneizados nos blocos experimentais, utilizando o critério de uniformidade das plantas e local de coleta das amostras em campo. Realizou-se um corte de uniformização a $5 \mathrm{~cm}$ do colo das plantas e, em seguida, foram aplicados os tratamentos.

Foram utilizadas cinco doses de $\mathrm{N}(0,100,200$, 300 e $\left.400 \mathrm{mg} \mathrm{dm}^{-3}\right)$ e cinco de $\mathrm{S}(0,10,20,30$ e $40 \mathrm{mg} \mathrm{dm}^{-3}$ ), as quais foram combinadas em estudo de superfície de resposta baseado em desenho experimental composto central modificado de um fatorial $5^{2}$ fracionado, de acordo com Littell \& Mott (1975). Assim, empregaram-se 13 combinações de N com S (em mg d m${ }^{-3}$ ): $0-0 ; 0-20 ; 0-40 ; 100-10$; 100-30; 200-0; 200-20; 200-40; 300-10; 300-30; 400-0; 400-20 e 400-40. O N foi fornecido como $\mathrm{NH}_{4} \mathrm{NO}_{3}$ e o $\mathrm{S}$ como $\mathrm{CaSO}_{4} \cdot 2 \mathrm{H}_{2} \mathrm{O}$, sendo a quantidade de Ca equilibrada em todas as parcelas experimentais pelo emprego de $\mathrm{CaCl}_{2}$. Após o corte de uniformização foram aplicados: $200 \mathrm{mg} \mathrm{dm}^{-3} \mathrm{de} \mathrm{P}, 150 \mathrm{mg} \mathrm{dm}^{-3} \mathrm{de} \mathrm{K}$ e $50 \mathrm{mg} \mathrm{dm}^{-3} \mathrm{de} \mathrm{Mg}$ a partir das seguintes fontes: $\mathrm{CaH}_{2} \mathrm{PO}_{4}, \mathrm{KH}_{2} \mathrm{PO}_{4}, \mathrm{KCl}$ e $\mathrm{MgCl}_{2} \cdot 6 \mathrm{H}_{2} \mathrm{O}$. As adubações com N, S e K foram repetidas após cada corte das plantas, enquanto a adubação com $\mathrm{Mg}$ foi de $20 \mathrm{mg} \mathrm{dm}^{-3}$, devido à não-aplicação de $\mathrm{P}$ a partir do primeiro crescimento e em conseqüência da diminuição no fornecimento de Ca após o primeiro corte das plantas. A adubação básica com os micronutrientes foi realizada com aplicação de reagentes com as seguintes fontes e quantidades: $\mathrm{H}_{3} \mathrm{BO}_{3}$ de $1,5 \mathrm{mg} \mathrm{dm}^{-3}$, $\mathrm{CuCl}_{2} \cdot 2 \mathrm{H}_{2} \mathrm{O}$ de $2,5 \mathrm{mg} \mathrm{dm}^{-3}, \mathrm{ZnCl}_{2}$ de $2,0 \mathrm{mg} \mathrm{dm}^{-3} \mathrm{e}$ $\mathrm{NaMoO}_{4} \cdot 2 \mathrm{H}_{2} \mathrm{O}$ de $0,25 \mathrm{mg} \mathrm{dm}^{-3}$, realizada uma vez, após o corte de uniformização. As adubações com macronutrientes foram estabelecidas mediante análise de solo, e as adubações com micronutrientes adaptadas de Mattos \& Monteiro (2003). As adubações foram realizadas em forma de solução, com exceção do $\mathrm{CaH}_{2} \mathrm{PO}_{4}$ que foi aplicado na forma de pó, em razão da sua baixa solubilidade. As características químicas da amostra superficial $(0-20 \mathrm{~cm})$ do solo coletado na área de pastagem em degradação, antes da aplicação dos tratamentos, foram: $\mathrm{pH}\left(\mathrm{CaCl}_{2}\right)=5,43$; M.O. e $\mathrm{N}$-total $=28$ e $1,75 \mathrm{~g} \mathrm{~kg}^{-1}$, respectivamente; $\mathrm{N}^{-\mathrm{NH}_{4}}{ }^{+}$ e N- $\mathrm{NO}_{3}{ }^{-}=8,40$ e $2,80 \mathrm{mg} \mathrm{kg}^{-1}$, respectivamente; P-resina e S-sulfato $=4,03$ e $4,32 \mathrm{mg} \mathrm{dm}^{-3}$, respectivamente; $\mathrm{K}, \mathrm{Ca}, \mathrm{Mg}, \mathrm{H}+\mathrm{Al}, \mathrm{SB}$ e $\mathrm{CTC}=2,28$; 14,$60 ; 10,40 ; 28,20 ; 27,28$ e $55,48 \mathrm{mmol}_{\mathrm{c}} \mathrm{dm}^{-3}$, respectivamente; $\mathrm{V}$ e $\mathrm{m}=49,17$ e $11,83 \%$, respectivamente.

A temperatura média na casa de vegetação durante o período experimental foi de $30^{\circ} \mathrm{C}$. A umidade do solo foi mantida por um sistema auto-irrigante subsuperficial, que permitia a reposição contínua de água de acordo com a necessidade da planta. Esse sistema possuía uma cápsula de cerâmica porosa (vela de filtro com diâmetro de $5 \mathrm{~cm}$ e altura de $7 \mathrm{~cm}$ ), inserida no solo na porção superior do vaso. Um microtubo flexível conectava a cápsula de cerâmica ao reservatório de nível constante (frasco mariotte) situado abaixo do vaso (Figura 1). O potencial de água no solo foi estabelecido pela altura da coluna de água entre o vaso e o reservatório $(30 \mathrm{~cm})$, correspondendo a uma tensão controlada de $3 \mathrm{kPa}$. Dessa forma, a evapotranspiração da gramínea garantia a reposição automática da água para o solo, tornando o sistema auto-irrigante. Uma escala de nível presa ao reservatório possibilitou quantificar o consumo de água em cada unidade experimental. Esse sistema de irrigação é um aprimoramento do modelo proposto por Montanheiro et al. (1979), o qual foi utilizado por Bataglia (1989) em experimento envolvendo fertilidade do solo e adaptado por Bonfim-Silva (2002). Os valores parciais de consumo de água foram integralizados como total acumulado em cada crescimento do capim.

A determinação da área foliar foi realizada por meio do aparelho integrador de área foliar, marca LI-COR, modelo LI 3100, e a avaliação da produção de massa seca da parte aérea foi feita por ocasião de cada corte das plantas. 


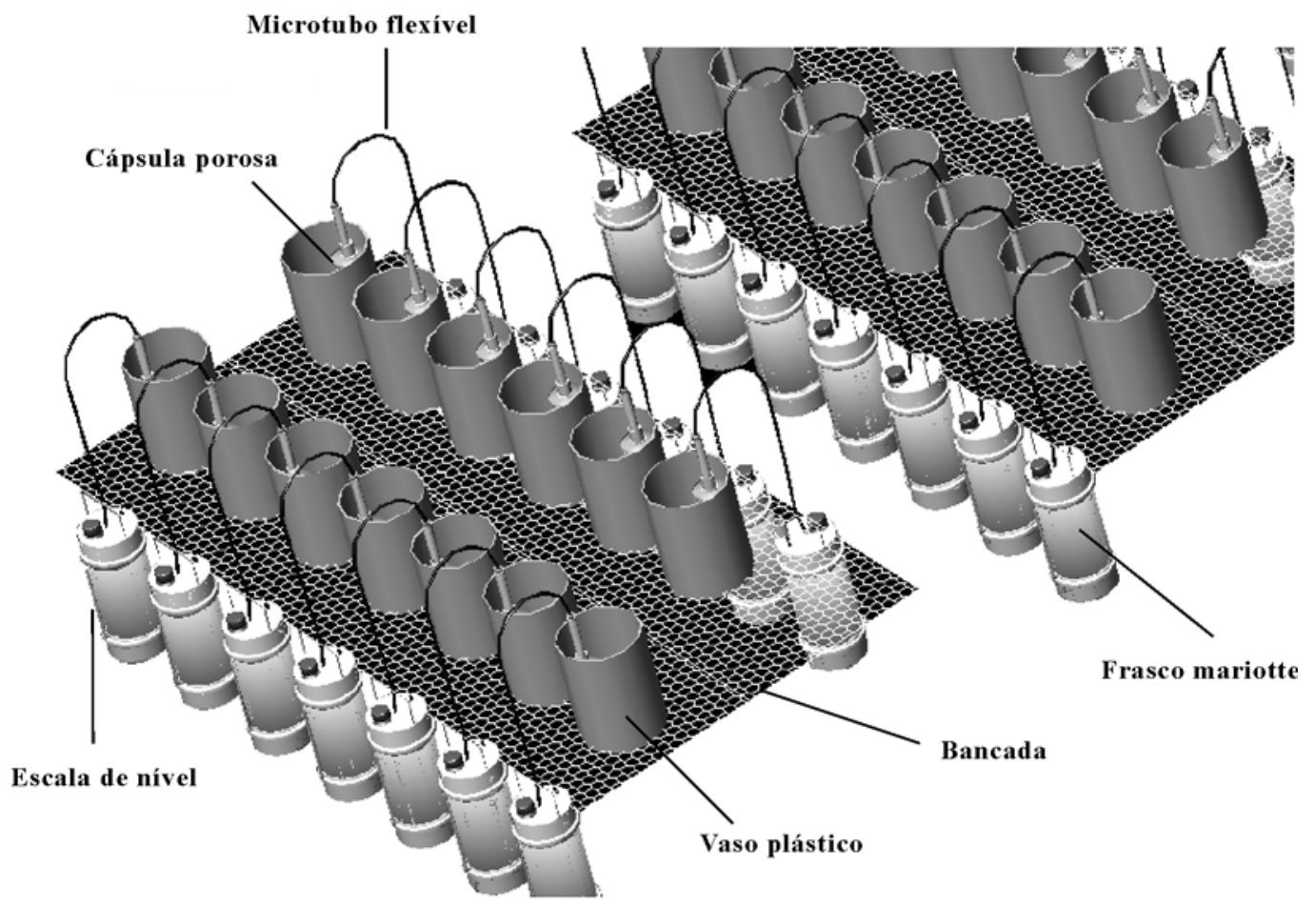

Figura 1. Representação do sistema de irrigação subsuperficial por tensão controlada com cápsula de porcelana porosa.

Foram feitos três cortes na parte aérea das plantas, a intervalos regulares de 30 dias de crescimento. A altura de corte foi de $5 \mathrm{~cm}$ do colo das plantas, para o primeiro e segundo cortes, e rente ao colo das plantas no terceiro corte. O material vegetal coletado nos três cortes foi secado em estufa de circulação forçada de ar, à temperatura de $65^{\circ} \mathrm{C}$, até massa constante, sendo posteriormente pesado em balança de precisão.

Com os resultados de consumo de água e de produção de massa seca total da parte aérea, calculouse a eficiência no uso de água pelo capim-braquiária, de acordo com as doses de $\mathrm{N}$ e de $\mathrm{S}$.

Todas as variáveis receberam o recomendado tratamento estatístico, com análise em superfície de resposta por meio do "Statistical Analysis System" (SAS, 1996). Inicialmente, foi realizada a análise de variância para as combinações das doses de $\mathrm{N}$ e S, e, considerando o nível de significância do teste $\mathrm{F}$ para essas combinações, efetuou-se o estudo de regressão polinomial (superfície de resposta) por meio do procedimento RSREG. Nos casos em que a interação $\mathrm{N}$ e S não foi significativa, efetuou-se o estudo de regressão de primeiro e segundo graus por meio do comando GLM. Utilizou-se o nível de significância de $5 \%$ em todos os testes estatísticos.

No caso do estudo de regressão polinomial, as doses de $\mathrm{N}$ e de $\mathrm{S}$ responsáveis pelos máximos valores foram obtidas por meio da saída dos resultados (output) da análise estatística do programa SAS. Para o estudo de regressão de segundo grau, as doses de $\mathrm{N}$ ou de $\mathrm{S}$ responsáveis pelos máximos valores foram obtidas por meio de derivada.

\section{RESULTADOS E DISCUSSÃO}

\section{Área foliar}

A interação entre doses de $\mathrm{N}$ e de $\mathrm{S}$ para a área foliar do capim-braquiária foi significativa no primeiro e no segundo crescimento, e em ambos os casos os resultados ajustaram-se a um modelo polinomial de regressão. No entanto, para o terceiro crescimento, foi verificada significância apenas para o efeito das doses de $\mathrm{N}$, com ajuste ao modelo quadrático de regressão.

No primeiro crescimento, por meio do estudo de superfície de resposta, constatou-se a área foliar máxima do capim-braquiária nas respectivas doses de $\mathrm{N}$ e de $\mathrm{S}$ de 368 e $35 \mathrm{mg} \mathrm{dm}^{-3}$ (Figura 2a). Assim, a maior área foliar ocorreu quando a relação N:S na adubação foi de 10,5:1. No segundo crescimento da gramínea, as doses de $\mathrm{N}$ e de $\mathrm{S}$ responsáveis pela máxima área foliar do capim foram de 328 e $45 \mathrm{mg} \mathrm{dm}^{-3}$ (Figura 2b), respectivamente, e a relação entre as doses de $\mathrm{N}$ e de $\mathrm{S}$ foi de 7:1. Observa-se que a dose de $\mathrm{S}$ para maximizar a área foliar no segundo crescimento excedeu a mais alta dose utilizada no intervalo experimental. Esse resultado corrobora o de Batista (2002), que, estudando o capim-marandu (Brachiaria 
brizantha cv. Marandu) submetido a doses desses nutrientes, verificou aumento na área foliar com as doses de $\mathrm{N}$ e S, obtendo o máximo valor de área foliar também na relação N:S na adubação de 7:1, no segundo crescimento do capim.

No terceiro crescimento do capim-braquiária, a área foliar foi significativamente influenciada pelas doses de $\mathrm{N}$, obtendo-se a máxima área na dose de $317 \mathrm{mg} \mathrm{dm}^{-3}$ (Figura 2c), o que confirma a importância do suprimento desse nutriente para a ampliação da área foliar do capim.

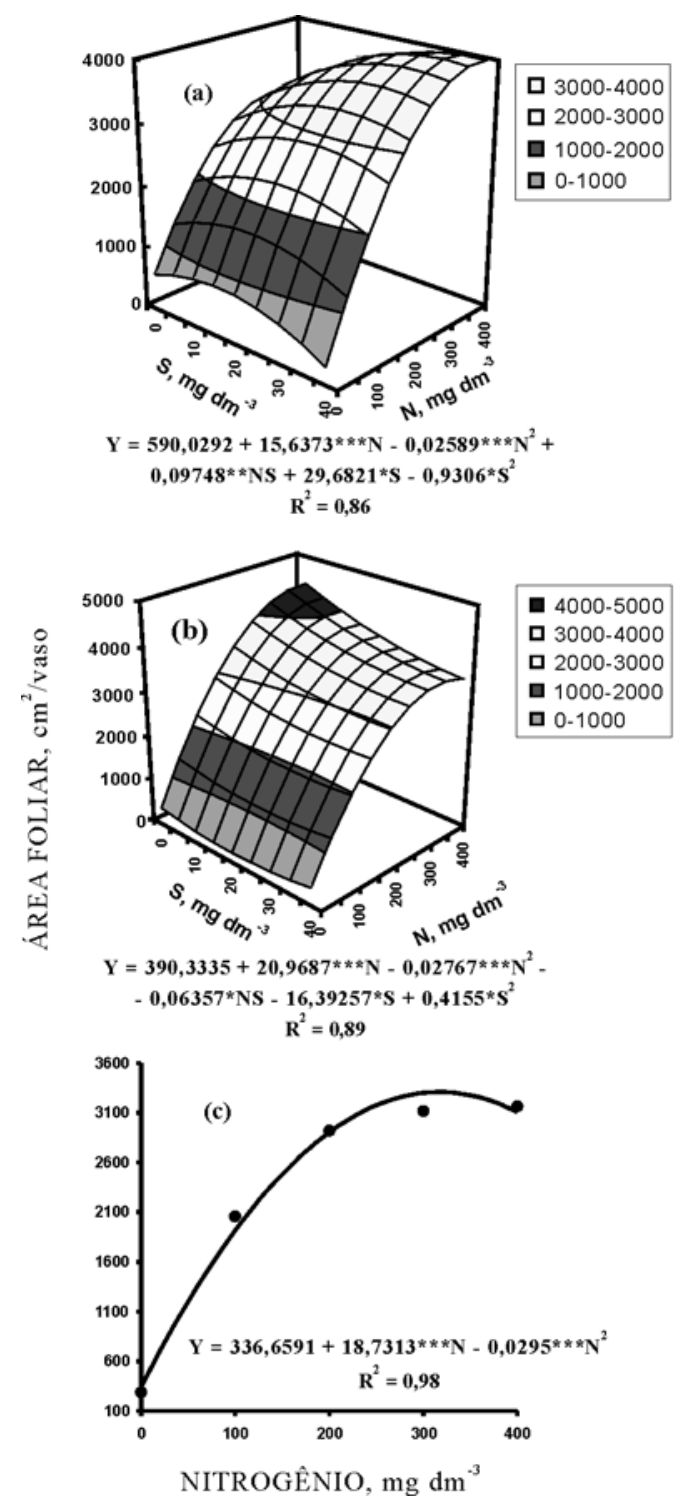

Figura 2. Área foliar do capim-braquiária no primeiro (a) e no segundo (b) crescimento de acordo com a adubação com doses de nitrogênio e enxofre, e no terceiro crescimento (c), considerando a adubação com doses de nitrogênio. ${ }^{* * * *}$; ** $\mathrm{e}^{*}$ : Significativo a 0,$1 ; 1$ e $5 \%$, respectivamente.
Na ausência desses nutrientes, a área foliar representou 15 e 11 \% daquelas obtidas como máximo, respectivamente para o primeiro e segundo crescimentos. No terceiro crescimento, a área foliar obtida no tratamento sem adubação com $\mathrm{N}$ representou $10 \%$ da máxima área foliar do capim-braquiária. Vários fatores podem ser limitantes para aumentar a área foliar do capim. Dentre esses, o déficit de água associado à falta de $\mathrm{N}$ são os mais comuns, e tanto um como o outro diminuem progressivamente a taxa fotossintética das folhas, a eficiência de conversão, a interceptação de luz e, conseqüentemente, a área foliar do vegetal (Nabinger, 1997). De acordo com Gastal \& Nelson (1994), o efeito do N na taxa de alongamento foliar decorre do maior acúmulo deste nutriente na zona de alongamento da folha, mais precisamente na região de divisão celular. Esses autores constataram alta correlação entre a quantidade de $\mathrm{N}$ contida nessa região e a taxa de expansão foliar. Também, Santos Júnior \& Monteiro (2003) verificaram que a área foliar do capim-marandu foi alterada positivamente pela aplicação de doses de $\mathrm{N}$.

No presente trabalho, pôde-se observar que no início da recuperação do capim-braquiária houve dependência do $\mathrm{S}$ à medida que se incrementou a dose de N. Mattos \& Monteiro (2003) também constataram interação significativa entre as doses de $\mathrm{N}$ e de $\mathrm{S}$ para a área foliar, visando recuperar o capim-braquiária em degradação, quando demonstraram a necessidade de incremento na dose de $\mathrm{S}$ sempre que o $\mathrm{N}$ era fornecido em doses mais elevadas. A não-dependência do $\mathrm{S}$ para a área foliar, no terceiro crescimento, está associada à reserva desse nutriente no capim, a qual teria sido suficiente para suprir sua exigência nutricional.

\section{Produção de massa seca da parte aérea}

A resposta do capim-braquiária em produção de massa seca da parte aérea foi diferenciada do primeiro para o segundo e terceiro crescimentos. A interação entre as doses de $\mathrm{N}$ e de $\mathrm{S}$ foi significativa para produção de massa seca da parte aérea no primeiro crescimento da gramínea, ajustando-se a modelo polinomial de regressão no estudo de superfície de resposta (Figura 3a).

No estudo de superfície de resposta para produção de massa seca da parte aérea no primeiro crescimento, observou-se que as doses de $\mathrm{N}$ e de $\mathrm{S}$ para a máxima produção de massa seca foram de 307 e $31 \mathrm{mg} \mathrm{dm}^{-3}$, respectivamente, com relação $\mathrm{N}$ :S na adubação de 10:1. Essa relação aproxima-se daquela encontrada para área foliar nesse mesmo crescimento do capim (10,5:1). Verificou-se ainda que, em condições de baixa disponibilidade desses nutrientes, as plantas tiveram crescimento reduzido da parte aérea. Esses resultados estão de acordo com os encontrados por Rodrigues (2002) e Mattos \& Monteiro (2003), indicando que o incremento de $\mathrm{N}$ leva à necessidade de suprir mais $\mathrm{S}$ para maximizar as respostas do capim-braquiária. 
No entanto, para o segundo e terceiro crescimentos foi verificada significância apenas para as doses de N, com ajustes a modelos quadráticos de regressão (Figura 3b, c). No segundo e terceiro crescimentos houve efeito isolado do $\mathrm{N}$ na produção de massa seca, sendo as doses de 366 e $288 \mathrm{mg} \mathrm{dm}^{-3}$, respectivamente, responsáveis pelas máximas produções do capimbraquiária (Figura 3b, c).

Hoffmann (1992) obteve a máxima produção de massa seca para o capim-braquiária nas doses isoladas de $\mathrm{N}$ e de $\mathrm{S}$ de 437 e $76 \mathrm{mg} \mathrm{kg}^{-1}$, respectivamente.

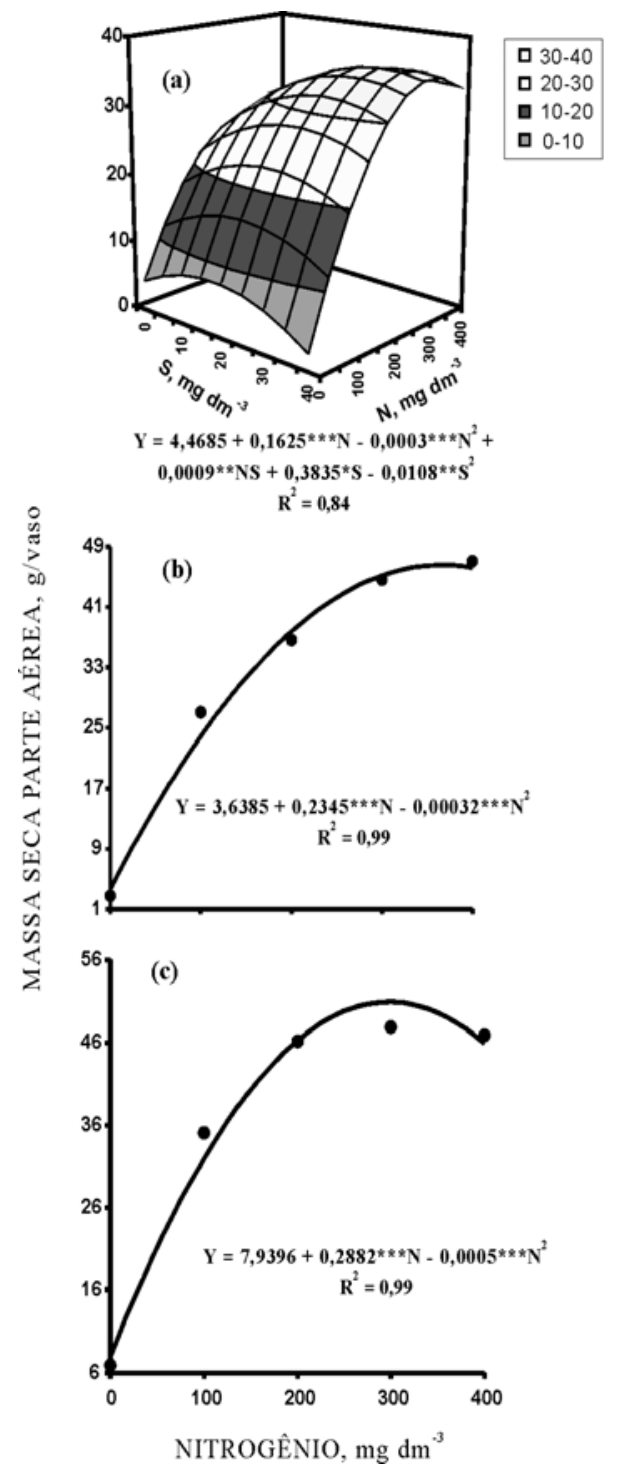

Figura 3. Produção de massa seca da parte aérea do capim-braquiária no primeiro crescimento (a), de acordo com a adubação com doses de nitrogênio e enxofre, e no segundo e terceiro crescimentos (b e c), considerando a adubação com doses de nitrogênio. ${ }^{* * * k} ;{ }^{* * *} \mathrm{e}^{*}$ Significativo a 0,$1 ; 1$ e $5 \%$, respectivamente.
Faquin et al. (1995) observaram, para o capimbraquiária, que as máximas produções de massa seca foram obtidas nas doses de $\mathrm{S}$ de 65 e $100 \mathrm{mg} \mathrm{kg}^{-1}$, respectivamente no primeiro e no segundo crescimento.

Aumento na produção de massa seca da parte aérea do capim-aruana (Panicum maximum cv. Aruana), com o incremento na adubação nitrogenada, foi constatado por Colozza (1998), que obteve o ponto de máxima produção de massa seca nas doses de $171 \mathrm{e}$ $332 \mathrm{mg} \mathrm{kg}^{-1}$, respectivamente para o primeiro e para o segundo crescimento do capim. Resultados semelhantes também foram relatados por Premazzi \& Monteiro (2002), que, ao avaliarem o crescimento do capim-Tifton 85 (Cynodon sp.), obtiveram os máximos valores estimados de produção de massa seca da parte aérea com o suprimento de $\mathrm{N}$ de 217 e $205 \mathrm{mg} \mathrm{kg}^{-1}$ de solo, no primeiro e no segundo corte, respectivamente.

\section{Consumo de água}

A interação entre as doses de $\mathrm{N}$ e de $\mathrm{S}$ foi significativa para o consumo de água por ocasião do primeiro crescimento do capim-braquiária (Figura 4a). No entanto, para o segundo e terceiro crescimento foi verificada significância apenas para as doses de $\mathrm{N}$, às quais se ajustaram modelos de regressão de segundo grau (Figura 4b, c).

No estudo da superfície de resposta para consumo de água no primeiro crescimento do capim-braquiária, pode-se observar que o máximo consumo de água ocorreu nas respectivas doses de $\mathrm{N}$ e de $\mathrm{S}$ de 302 e $39 \mathrm{mg} \mathrm{dm}{ }^{-3}$, com relação N:S na adubação de 8:1. No segundo e terceiro crescimentos obtiveram-se os máximos consumos de água nas doses de $\mathrm{N}$ de $347 \mathrm{e}$ $281 \mathrm{mg} \mathrm{dm}^{-3}$, respectivamente. O consumo de água pelo capim-braquiária apresentou resposta semelhante à da produção de massa seca e à da área foliar. As doses necessárias para obtenção dos máximos valores dessas duas variáveis foram bem próximas. Isso ocorreu provavelmente pelo fato de a evapotranspiração da cultura ser influenciada sobretudo pela área foliar e, conseqüentemente, pela maior produção de massa seca. Como as unidades experimentais eram vasos com área exposta de solo relativamente pequena, certamente ocorreram perdas mínimas de água por evaporação do solo, sendo a saída de água do sistema controlada principalmente pela superfície das folhas do capim. Esses resultados corroboram os relatados por Freire (1991) e Silva et al. (2001), que observaram aumento no consumo de água com o incremento das doses de $\mathrm{N}$ por plantas de milho e milheto, respectivamente.

De acordo com Hanson \& Orloff (1998) e Oliveira et al. (2003), existe relação positiva entre a produção de massa seca e a evapotranspiração da cultura, havendo estreita e positiva relação entre a produção de massa seca e a eficiência no uso de água, 

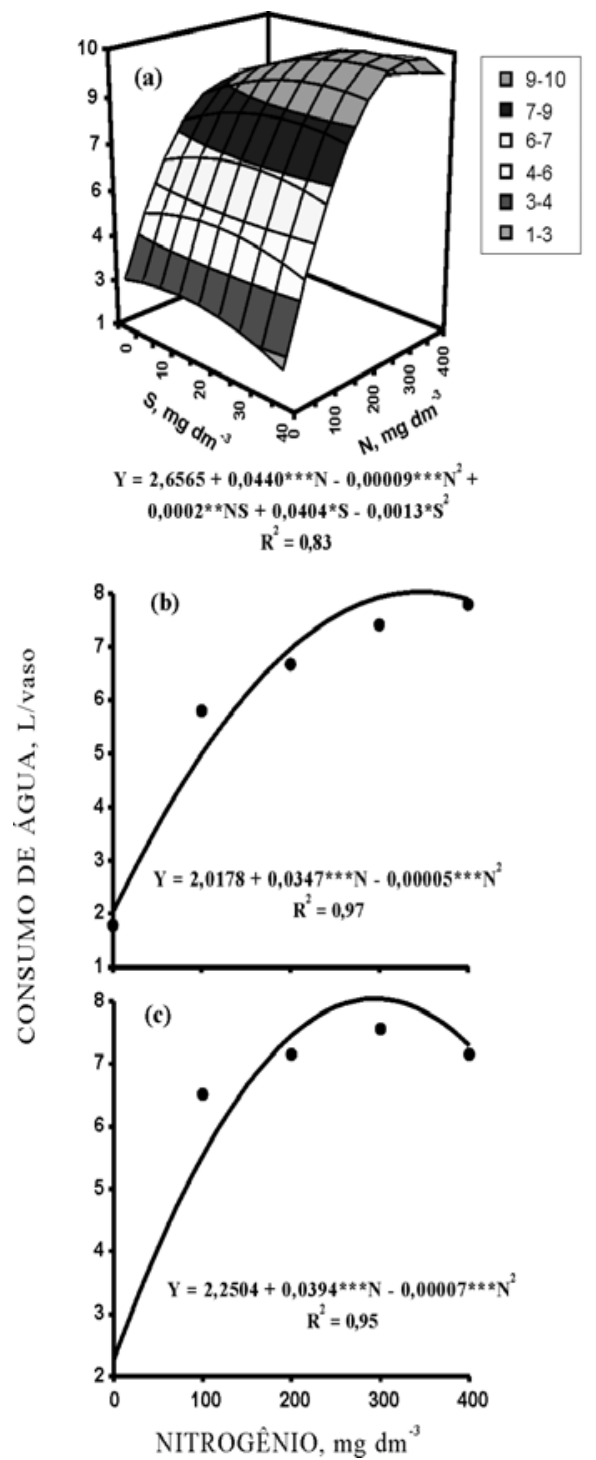

Figura 4. Consumo de água pelo capim-braquiária no primeiro crescimento (a), de acordo com a adubação com doses de nitrogênio e enxofre, e no segundo e terceiro crescimentos (b e c), considerando a adubação com doses de nitrogênio. ${ }^{* * * * k}$; ${ }^{* * *}$ e * Significativo a 0,$1 ; 1$ e $5 \%$, respectivamente.

independentemente do ambiente em estudo. Vale ressaltar que, no presente trabalho, a maior produção de massa seca do capim-braquiária foi obtida mediante o incremento das doses de $\mathrm{N}$ e de $\mathrm{S}$ no primeiro crescimento e de doses isoladas de $\mathrm{N}$ no segundo e no terceiro crescimento, tendo a água a mesma disponibilidade em todas as unidades experimentais.

\section{Eficiência no uso de água}

No primeiro crescimento do capim-braquiária ocorreu significância para a interação entre as doses de $\mathrm{N}$ e de $\mathrm{S}$ na eficiência de uso da água pelo capim- braquiária, com ajuste dos resultados a modelo polinomial de regressão. No segundo e terceiro crescimentos, a eficiência no uso de água pelo capim mostrou significância apenas para as doses de N, que foi representada por modelos quadráticos de regressão.

No primeiro crescimento, verificou-se, por meio do estudo de superfície de resposta, que as doses de $\mathrm{N} \mathrm{e}$ de $\mathrm{S}$ para a máxima eficiência no uso de água ocorreram, respectivamente, nas doses de 304 e $25 \mathrm{mg} \mathrm{dm}^{-3}$, com relação N:S na adubação de 11:1 (Figura 5a). Esses resultados indicam a contribuição positiva do $\mathrm{N}$ e do $\mathrm{S}$ na eficiência no uso de água pelo capim-braquiária, com maior produção de massa seca por unidade de consumo de água à medida que se incrementaram as doses desses dois nutrientes. Assim, quando se compara o tratamento em que não se realizou aplicação de $\mathrm{N}$ e $\mathrm{S}$ com aqueles que receberam doses desses dois nutrientes, observa-se que na presença destes o capim aproveitou melhor a água disponível no solo para produzir maior quantidade de massa seca. Pesquisas têm mostrado maior eficiência no uso de água com o incremento no suprimento de $\mathrm{N}$, com conseqüente aumento na produção de gramíneas (Lahiri, 1980; Freire, 1991). No que se refere à interação entre o $\mathrm{N}$ e o $\mathrm{S}$ para eficiência no uso de água, não se encontrou trabalho que mostrasse esse efeito em gramíneas forrageiras.

No presente trabalho foi demonstrado que a eficiência no uso de água pode ser melhorada mediante inclusão do S na adubação. Dessa forma, pode-se verificar aumento na relação massa seca:consumo de água de acordo com as doses de $\mathrm{N}$ e de $\mathrm{S}$ aplicadas, confirmando assim a hipótese aqui proposta.

No segundo e terceiro crescimentos, o N desempenhou papel isolado na eficiência no uso de água, com a máxima eficiência obtida nas doses de 317 e $305 \mathrm{mg} \mathrm{dm}^{-3}$, respectivamente (Figura 5b, c). Nesses crescimentos, a máxima eficiência no uso de água pelo capim foi superior àquela observada no primeiro crescimento. Assim, no segundo e terceiro crescimentos, a relação massa seca:consumo de água foi até próximo de 7, enquanto no primeiro crescimento essa relação chegou próxima de 3,5. Isso significa que o capim-braquiária utilizou a água de forma mais eficiente após o primeiro crescimento, o que possivelmente está associado à recuperação do sistema radicular, que a partir do segundo crescimento passou a destinar mais energia para o crescimento da parte aérea.

Em estudo relativo aos efeitos do estresse hídrico e da adubação nitrogenada em medidas de crescimento, concentração de $\mathrm{N}$ e eficiência no uso de água pelo milho, Freire (1991) verificou que a adubação nitrogenada promoveu maior ajustamento osmótico nas plantas constantemente estressadas, com conseqüente maior acumulação relativa de massa seca e maior eficiência do uso de água. Mattos et al. (1997) constataram que as doses de $\mathrm{N}$, juntamente com a irrigação, proporcionaram acréscimo na produção total 

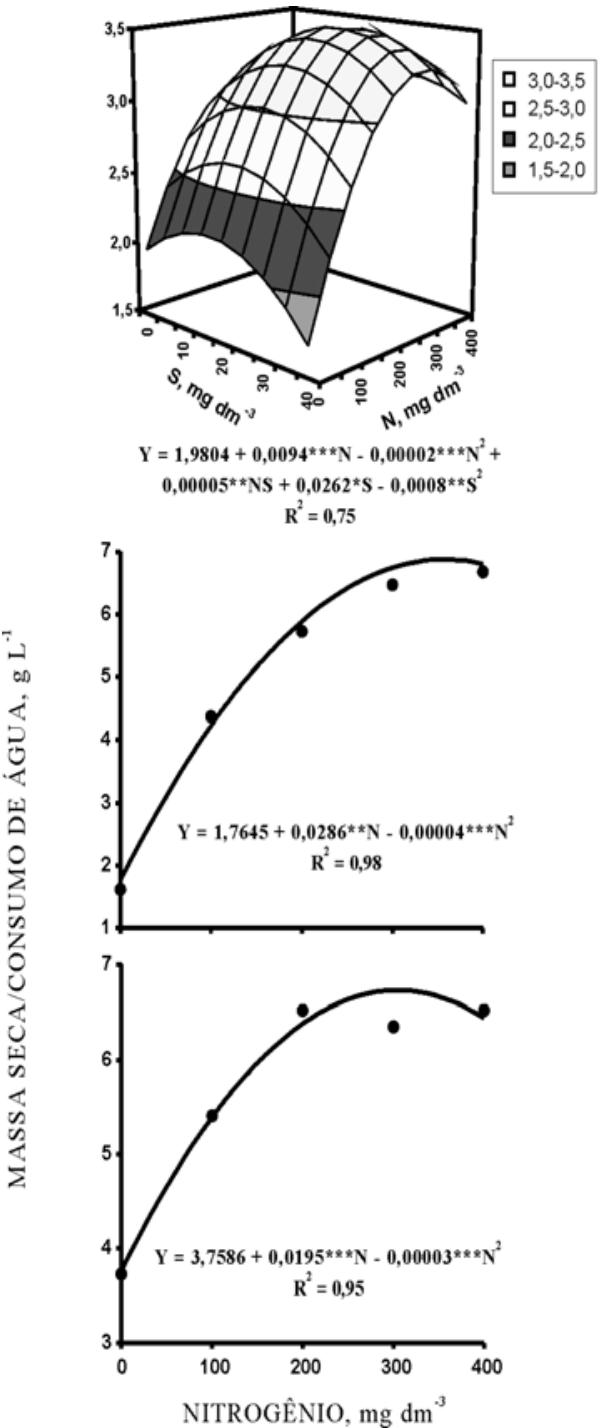

Figura 5. Eficiência do capim-braquiária no uso de água no primeiro crescimento (a), considerando a adubação com doses de nitrogênio e enxofre, $e$ no segundo e terceiro crescimentos (b e c), considerando a adubação com doses de nitrogênio. ${ }^{* * * *}$; ${ }^{* *}$ e * Significativo a 0,$1 ; 1$ e $5 \%$, respectivamente.

de massa seca do milheto e teosinto (Euchlaena mexicana). Trabalho realizado por Pieterse et al. (1997), com cultivares de Panicum maximum, comparando doses de $\mathrm{N}$, mostrou que a eficiência de uso do adubo nitrogenado dependeu da umidade do solo. Esses autores demonstraram a importância do $\mathrm{N}$ e da disponibilidade de água no solo para a produção das gramíneas. No presente trabalho, a umidade do solo foi controlada por meio do sistema auto-irrigante, não sendo, desse modo, o fornecimento de água uma fonte de variação no estudo. Os resultados deste trabalho estão bem próximos daqueles obtidos por Silva et al. (2001), os quais relataram maior produção de massa seca pelo milheto com menor consumo de água à medida que aumentaram a dose fornecida de $\mathrm{N}$ e que a máxima eficiência do uso de água ocorreu na dose de $\mathrm{N}$ de $350 \mathrm{mg} \mathrm{dm}^{-3}$.

De maneira geral, pode-se observar que na recuperação do capim-braquiária a adubação com $\mathrm{S}$ foi mais efetiva no primeiro crescimento em todas as variáveis estudadas, com exceção da área foliar. Isso provavelmente está associado à reserva de $\mathrm{S}$ feita pela planta no primeiro crescimento, que teria sido suficiente para o segundo e o terceiro crescimentos, o que pode ter ocorrido devido à recuperação do sistema radicular do capim, que a partir do segundo crescimento direcionou energia para o desenvolvimento da parte aérea.

\section{CONCLUSÕES}

1. A interação entre as doses de $\mathrm{N}$ e de $\mathrm{S}$ foi significativa no primeiro crescimento do capim para a área foliar, a produção de massa seca, o consumo de água e a eficiência no uso de água.

2. Com exceção da área foliar, o $\mathrm{N}$ teve efeito isolado no segundo e no terceiro crescimento do capim.

3. O fornecimento simultâneo de $\mathrm{N}$ e $\mathrm{S}$ na adubação, em relação de 7:1 a 11:1, contribui de forma positiva para recuperação do capim-braquiária, aumentando a área foliar, a produção de massa seca e melhorando a eficiência no uso de água.

\section{LITERATURA CITADA}

BATAGLIA, O.C. Sistema de irrigação em vasos para experimentos de adubação. R. Bras. Ci. Solo, 13:81-86, 1989 .

BATISTA, K. Respostas do capim-marandu a combinações de doses de nitrogênio e enxofre. Piracicaba, Escola Superior de Agricultura "Luiz de Queiroz", 2002. 91p. (Tese de Mestrado)

BONFIM-SILVA, E.M. Níveis críticos de fósforo para Brachiaria brizantha (Hochst ex A. Rich.) Stapf. Cv. Marandu em solos de referência de Pernambuco. Recife, Universidade Federal Rural de Pernambuco, 2002. 57p. (Tese de Mestrado)

CARVALHO, M.C.S. Práticas de recuperação de uma pastagem degradada e seus impactos em atributos físicos, químicos e microbiológicos do solo. Piracicaba, Escola Superior de Agricultura Luiz de Queiroz, 1999. 103p. (Tese de Doutorado)

COLOZZA, M.T. Rendimento e diagnose foliar dos capins Aruana e Mombaça cultivados em Latossolo VermelhoAmarelo adubado com doses de nitrogênio. Piracicaba, Escola Superior de Agricultura Luiz de Queiroz, 1998. 127p. (Tese de Doutorado) 
FAQUIN, V.; HOFFMANN, C.R.; EVANGELISTA, A.R. \& GUEDES, G.A.A. O potássio no crescimento da braquiária e do colonião em amostras de um Latossolo da região noroeste do Paraná. R. Bras. Ci. Solo, 19:87-97, 1995.

FREIRE, F.J. Efeito do estresse hídrico e da adubação nitrogenada em parâmetros de crescimento de milho (Zea mays L.), teor de nitrogênio e eficiência no uso de água. Recife, Universidade Federal Rural de Pernambuco, 1991. 156p. (Tese de Mestrado)

GASTAL, F. \& NELSON, C.J. Nitrogen use within the growing leaf blade of tall fescue. Plant Physiol., 105:191-197, 1994.

HANSON, B. \& ORLOFF, S. Double yield with half the water: Is it possible? In: 1998 CALIFORNIA/NEVADA ALFAFA SYMPOSIUM, 1998, Davis. Proceedings. Davis, University of Califórnia, 1998. p.75-87.

HOFFMANN, C.R. Nutrição mineral e crescimento de braquiária e de colonião, sob influência das aplicações de nitrogênio, fósforo, potássio e enxofre em Latossolo de região noroeste do Paraná. Lavras, Escola Superior de Agricultura de Lavras, 1992. 204p. (Tese de Mestrado)

LAHIRI, A.N. Interaction of water stress and mineral nutrition on growth and yield. In: TURNER, N.C. \& KRAMER, P.L. Adaptation of plants to water and high temperature stress. New York, John Wiley \& Sons, 1980. p.341-352.

LITTELL, R.C. \& MOTT, G.O. Computer assisted design and analysis of response surface experiments in agronomy. Soil Crop Sci. Soc. Fla. Proc., 34:94-97, 1975.

MATTOS, J.L.S.; PINTO, J.C.; OLIVEIRA, L.E.M. \& MORAIS, A.R. Influência da disponibilidade de água e nitrogênio sobre características morfológicas de gramíneas forrageiras. Ci. Agrotec., 21:495-501, 1997.

MATTOS, W.T. \& MONTEIRO, F.A. Produção e nutrição de capim-braquiária em função de doses de nitrogênio e enxofre. B. Ind. Anin., 60:1-10, 2003.

MONTANHEIRO, M.N.; SAITO, S.N.T.; REICHARDT, K. \& LIBARDI, P.L. Controle de tensões de água no solo em vasos com feijoeiro (Phaseolus vulgaris). In: CONGRESSO BRASILEIRO DE CIÊNCIA DO SOLO, 17., Manaus, 1979, Anais. Campinas, Sociedade Brasileira de Ciência do Solo, 1979. p.68.

NABINGER, C. Eficiência do uso de pastagens: Disponibilidade e perdas de forragem. In: SIMPÓSIO SOBRE MANEJO DA PASTAGEM, 14., Piracicaba, 1997. Anais. Piracicaba, FEALQ, 1997. p.213-215.
OLIVEIRA, W.S.; OLIVEIRA, P.P.A; CORSI, M.; TRIVELIN, P.C.O.O. \& TSAI, S.M. Disponibilidade hídrica relacionada ao conteúdo de nitrogênio e à produtividade da alfafa (Medicago sativa L.). R. Bras. Zootec., 32:1275-1286, 2003.

PIETERSE, P.A.; RETHMAN, N.F.G. \& van BOSCH, J. Production, water use efficiency and quality of two cultivars of Panicum maximum at different levels of nitrogen fertilization. Trop. Grass., 31:117-123, 1997.

PREMAZZI, L.M. \& MONTEIRO, F.A. Produção de capimTifton 85 submetido a doses e épocas de aplicação de nitrogênio após o corte. B. Ind. Anim., 59:1-16, 2002.

RODRIGUES, R.C. Calcário, nitrogênio e enxofre para recuperação do capim-braquiária cultivado em solo proveniente de uma pastagem degradada. Piracicaba, Escola Superior de Agricultura Luiz de Queiroz, 2002. 141p. (Tese de Mestrado)

SANTOS JÚNIOR, J.D.G. \& MONTEIRO, F.A. Nutrição de capim-marandu submetido a doses de nitrogênio e idade de crescimento. B. Ind. Anim., 60:139-146, 2003.

SAS INSTITUTE. The SAS System for Windows, Release 6.08. Cary, 1996. 633p.

SILVA, T.J.A.; BONFIM-SILVA, E.M.; SILVA NETO, M.M. \& MÉLO, R.F. Níveis de nitrogênio e seus efeitos na evapotranspiração do milheto cultivado em um solo da Zona da Mata de Pernambuco. In: CONGRESSO LATINO-AMERICANO DE CIÊNCIA DO SOLO, 15., Varadero, 2001. Anais. Varadero, 2001. CD-ROM

SORIA, L.T.; COELHO, R.D.; HERLING, V.R. \& PINHEIRO, V. Respostas do capim-Tanzânia à aplicação de nitrogênio e lâminas de irrigação. I: Produção de forragem. R. Bras. Eng. Agríc. Amb., 7:430-436, 2003.

SOUZA NETO, J.M. \& PEDREIRA, C.G.S. Caracterização do grau de degradação de pastagens. In: SIMPÓSIO SOBRE MANEJO DE PASTAGEM, 21., Piracicaba, 2004. Anais. Piracicaba, FEALQ, 2004. p.7-31.

TAIZ, L. \& ZEIGER, E. Fisiologia vegetal. Porto Alegre, Artmed, 2004. 719p.

WERNER, J.C. \& MONTEIRO, F.A. Respostas das pastagens à aplicação de enxofre. In: SIMPÓSIO: ENXOFRE E MICRONUTRIENTES NA AGRICULTURA BRASILEIRA, Londrina, 1988. Anais. Londrina, Embrapa/CNPS/IAPAR, 1988. p.87-102. 